\title{
Direct pulp capping versus pulpotomy with MTA for carious primary molars: a randomised clinical trial
}

\author{
Dimitraki, D ; Papageorgiou, S N ; Kotsanos, N
}

\begin{abstract}
Aim: Aim of this randomised clinical trial was to compare the outcome of direct pulp capping (DPC) versus pulpotomy, both with MTA, for carious primary molars. Methods: Healthy, cooperative children aged 3-9 years with at least one deep carious primary molar requiring vital pulp therapy were included. Data on the primary outcome (all-cause failure) and secondary outcomes (clinical or radiographic failure) were collected blindly semi-annually for a minimum of 1 year up to 3 years and analysed with survival analysis and generalised linear regression at alpha $=5 \%$. Results: A total of 74 children were randomly allocated on 1:1 basis to DPC (35 children; 40 teeth) or pulpotomy (39 children; 57 teeth). Survival from all-cause failure was $79.7 \%$ [ $95 \%$ confidence interval (CI) 69.3-86.9\%] at 12 months and 66.0\% (95\% CI 53.4-76.0\%) at 24 months which remained stable up to 36 months, with no differences between groups $(\mathrm{P}>0.05)$. No significant difference was found in the survival rate of the two groups for all-cause [hazard ratio $(\mathrm{HR})=0.95 ; 95 \% \mathrm{CI} 0.45-2.01 ; \mathrm{P}=0.88$ ], clinical $(\mathrm{HR}=0.74$; 95\% CI 0.0.19-2.92; $\mathrm{P}=0.66)$, or radiographic failure $(\mathrm{HR}=0.80 ; 95 \% \mathrm{CI} 0.0 .36-1.82 ; \mathrm{P}=0.60)$ throughout the 3-year follow-up. Regression analysis indicated that needing a second attempt for haemorrhage control was associated with higher clinical failure rate. All-case failure was significantly different for class II versus occlusal cavities and in the latter cavities pulpotomy performed better $(\mathrm{P}<0.001)$. Conclusion: The results of the current trial indicate that both DPC and pulpotomy can be reliable options for the treatment of deep carious primary molars in cooperative children, in carefully selected cases. Keywords: Direct pulp capping; MTA; Primary molars; Pulpotomy; Randomised clinical trial.
\end{abstract}

DOI: https://doi.org/10.1007/s40368-019-00419-7

Posted at the Zurich Open Repository and Archive, University of Zurich

ZORA URL: https://doi.org/10.5167/uzh-186062

Journal Article

Accepted Version

Originally published at:

Dimitraki, D; Papageorgiou, S N; Kotsanos, N (2019). Direct pulp capping versus pulpotomy with MTA for carious primary molars: a randomised clinical trial. European Archives of Paediatric Dentistry, 20(5):431-440.

DOI: https://doi.org/10.1007/s40368-019-00419-7 


\section{Direct pulp capping versus pulpotomy with MTA for carious primary molars: a randomized clinical trial}

D. Dimitraki ${ }^{1}$ S.N. Papageorgiou² $\bullet$ N. Kotsanos ${ }^{2}$

1 Department of Paediatric Dentistry, Dental School, University of Thessaloniki, Greece

2 Clinic of Orthodontics and Pediatric Dentistry, Center of Dental Medicine, University of Zurich, Zurich,

Switzerland

Corresponding Author: Dimitraki Dionysia; ddionysi@gmail.com.

\section{Keywords}

Direct pulp capping $\bullet$ pulpotomy $\bullet$ MTA $\bullet$ primary molars $\bullet$ randomized clinical trial

Conflict of Interest: The authors declare that they have no conflict of interest.

Acknowledgement: The authors would like to thank all postgraduate residents and clinic supervisors for their assistance in this study. The MTA used in the study procedures was provided by Medcem $\mathrm{GmbH}$, Weinfelden, Switzerland. Preliminary results of this study were published in the $13^{\text {th }}$ EAPD Congress in Belgrade and were awarded with the "Young Scientist Research Award".

Words in abstract: 250

Words in text: 4650

ORCIDs

D. Dimitraki: 0000-0003-4408-4907

S.N. Papageorgiou: 0000-0003-1968-3326

N. Kotsanos: 0000-0001-5298-8653 


\section{Abstract}

Aim: Aim of this randomized clinical trial was to compare the outcome of direct pulp capping (DPC) versus pulpotomy, both with MTA, for carious primary molars.

Methods: Healthy, cooperative children aged 3-9 years with at least one deep carious primary molar requiring vital pulp therapy were included. Data on the primary outcome (all-cause failure) and secondary outcomes (clinical or radiographic failure) were collected blindly semi-annually for a minimum of 1 year up to 3 years and analyzed with survival analysis and generalized linear regression at alpha $=5 \%$.

Results: A total of 74 children were randomly allocated on 1:1 basis to DPC (35 children; 40 teeth) or pulpotomy (39 children; 57 teeth). Survival from all-cause failure was $79.7 \%$ (95\% Confidence Interval $[\mathrm{Cl}]=69.3 \%-86.9 \%)$ at 12 months and $66.0 \%(95 \% \mathrm{Cl}=53.4 \%-76.0 \%)$ at 24 months which remained stable up to 36 months, with no differences between groups $(P>0.05)$. No significant difference was found in the survival rate of the two groups for all-cause (Hazard Ratio $[\mathrm{HR}]=0.95 ; 95 \% \mathrm{Cl}=0.45-2.01$; $\mathrm{P}=0.88)$, clinical $(\mathrm{HR}=0.74 ; 95 \% \mathrm{Cl}=0.0 .19-2.92 ; \mathrm{P}=0.66)$, or radiographic failure $(\mathrm{HR}=0.80 ; 95 \%$ $\mathrm{Cl}=0.0 .36-1.82 ; \mathrm{P}=0.60)$ throughout the 3-year follow-up. Regression analysis indicated that needing a second attempt for haemorrhage control was associated with higher clinical failure rate. All-case failure was significantly different for class II versus occlusal cavities and in the latter cavities pulpotomy performed better $(P<0.001)$.

Conclusion: The results of the current trial indicate that both DPC and pulpotomy can be reliable options for the treatment of deep carious primary molars in cooperative children, in carefully selected cases. 


\section{Introduction}

\section{Rationale}

Dental caries is one of the most common chronic diseases among children, with considerable variation in its clinical manifestation, which can affect pulp vitality and ultimately lead to infection, abscesses, fistulae, and subsequent early tooth loss (Dye et al. 2015). The decision to treat deep caries of primary teeth stems from the need to restore them in order to keep them asymptomatic and functional until they are replaced naturally by their permanent successors to avoid adverse effects (Rönnerman 1977; Smaïl-Faugeron et al. 2018). Interventions for treating deep carious lesions in teeth with no history of pain or teeth with reversible pulpitis are referred as vital pulp therapies, which may consist of the placement of a protective liner, indirect pulp treatment, direct pulp capping (DPC), and pulpotomy (Fuks et al. 2006; AAPD 2014).

While the first three treatment options are the least invasive ones, pulpotomy is considered the gold standard in paediatric dentistry with average success rate of $82.6 \%$ and small difference in its success rate with the use of either Mineral Trioxide Aggregate (MTA) or formocresol (89.6\% and $85.0 \%$, respectively) (Coll et al. 2017). Pulpotomy after an iatrogenic or carious pulp exposure that lacks radicular pathology consists of removal of the coronal pulp, haemorrhage control, and capping of the radicular pulp with a variety of materials, if appropriate (i.e. if there is no suppuration, purulence, and profuse bleeding) (AAPD 2014). The list of materials used to treat the amputated radicular pulp include Buckley's solution, ferric sulfate, formocresol, sodium hypochlorite, or saline solution (Huth et al. 2005; Vostatek et al. 2011; AAPD 2014; Asgary et al. 2014) and then traditionally capped with calcium hydroxide paste. Other newer materials used to cap the amputated pulp include zinc oxide, eugenol paste, Portland cement, nanocrystalline hydroxyapatite paste, Biodentine, or MTA, with the latter increasingly gaining ground over older materials due to its performance (Innes 2007; $\mathrm{Ng}$ and Messer 2008; Shayegan et al. 2010; AAPD 2014; Bani et al. 2017). Pulpotomy is considered successful when there is lack of any pain, sensitivity, swelling, furcation radiolucency, pathologic external / internal root resorption, and no harm to the permanent successor (AAPD 2014).

On the other hand, DPC has been less popular in previous years among paediatric dentists due to the notion that its results are inferior to pulpotomy (Rodd et al. 2006). A recent meta-analysis however, indicated that the 24-month overall success rate of DPC irrespective of the capping agent was $88.8 \%$ and that choice of the capping agent had no effect on success $(P=0.56)$ (Coll et al. 2017). 
Indications for DPC include teeth that are one to two years prior to their exfoliation and have traumatic or mechanical "pinpoint" exposure of normal pulps during cavity preparation, therefore not including cases of carious pulp exposure (Fuks 2002; Rodd et al. 2006; Fuks 2008; AAPD 2014). Traditionally, calcium hydroxide has been used as the capping agent in DPC of primary teeth (Tuna and Olmez 2008; Asl Aminabadi et al. 2013; AAPD 2014), but several other materials like formocresol, zinc oxide, glass ionomer cement, nanohydroxyapatite, Portland cement, calcium enriched paste/mixture (CEM), calcium sulfate, bioactive glass/bioglass, enamel matrix derivative (EMD), simvastatin, or MTA have also been clinically tested (Fuks 2002; Huth et al. 2005; Fuks et al. 2006; Haghgoo et al. 2007; Innes 2007; Dunston and Coll 2008; Garrocho-Rangel et al. 2009; Fallahinejad Ghajari et al. 2010; Shayegan et al. 2010; Asl Aminabadi et al. 2013; Ulusoy et al. 2014; Haghgoo et al. 2015). While there is no indication that chosen material plays a major role in the prognosis of teeth after DPC (Coll et al. 2017), microleakage prevention via proper restoration seal and maintenance of tooth vitality with formation of a reparative dentin bridge have been closely linked to the success of DPC (Farooq et al. 2000; AAPD 2014).

\section{Aim}

Existing evidence on vital pulp therapy is considered to be moderate to very low, due to the lack of high quality studies (Rodd et al. 2006; Schwendicke et al. 2016; Dhar et al. 2017, Smaïl-Faugeron et al. 2018), while the American Academy of Pediatric Dentistry encourages additional research for consistently successful and predictable techniques using biologically-compatible medicaments for vital and non-vital primary and immature permanent teeth (AAPD 2014; Dhar et al. 2017). Therefore, the aim of the present trial was to provide evidence on the survival of primary molars with exposed pulps after DPC or pulpotomy with MTA as the capping agent. The null hypothesis was that there is no difference in the 3-year survival between these two treatment alternatives.

\section{Materials and methods}

\section{Ethical Approval and Consent}

This study was approved by the Ethics Committee of the Aristotle University of Thessaloniki Dental School (307/July 6, 2012). Parents / guardians of all prospective patients were given verbal and written 
details of the procedures and their required compliance to the follow-up program, and were asked to sign the informed consent form before participating.

\section{Study Population}

The study population consisted of healthy (ASA I, II), cooperative patients (Frankl scale + and ++ ) aged 3 to 9 years old, attending the postgraduate Paediatric Dentistry Clinic of the Aristotle University of Thessaloniki for regular dental care. All patients received clinical and radiographic examination, oral prophylaxis, fluoride application, and dietary / oral health consultation prior to receiving restorations, following the Clinic's protocol. As a result, all restorative procedures were carried out at the patient's third appointment in the Clinic or later.

\section{Sample size calculation}

Sample size calculation for this study was based on the MTA pulpotomy failure rate from another study (Sonmez et al. 2008), assuming a relative risk reduction of $50 \%$, alpha of $5 \%$ and power of $80 \%$. This indicated that 35 teeth per group (70 in total) would be needed to identify the pre-specified failure risk reduction with a chi-square test, which was increased by $10 \%$ to 40 teeth per group to account for dropouts.

\section{Randomisation}

Each patient received in random only one of the following two procedures on all eligible teeth (first or second primary molars): pulpotomy or DPC. Randomisation was performed on patient level and patients were randomised until both groups had at least 40 teeth treated. Randomisation upon patient entering the study was carried out using a list of random numbers generated online with a randomisation program (www.randomizer.org) and the results were exported in an excel data form. Prior to the programmed appointment, the treating clinician would ask the dental nurse to check the randomisation list and inform the clinician which procedure had to be followed.

\section{Eligibility Criteria}

Eligible for this trial were carious first and second primary molars requiring vital pulp therapy. Inclusion criteria demanded that the teeth should be restorable, have no history of pain or that the pain that 
subsides upon removal of the stimulus. Radiographically, root resorption should be minimal (limited to $1 / 3$ of the root), there should be absence of furcation/periapical lesions, and there should be caries in the inner half of the dentin approaching the pulp. Routine caries removal was suspected to lead in pulp exposure. Bleeding in either group should be able to be controlled within 5 minutes' time. If haemorrhage control was not successful, the pulp condition was deemed inappropriate for the allocated protocol treatment and the tooth was excluded from the trial and treated accordingly. Root resorption exceeding $1 / 3$ of the root, radiographic apical pathology, any soft and hard tissue pathology, pathologic tooth movement, and automatic pain were considered contraindications for the inclusion of the tooth in the trial's protocol.

\section{Treatment procedures}

All treatment procedures were carried out by the six postgraduate students of the Clinic. These were previously trained at a series of practical hands-on specially designed seminars to improve their clinical skills by the senior author (NK, faculty member) until they could similarly and adequately perform both treatment procedures, i.e. DPC and pulpotomy by MTA plus tooth restoration. All stages of the procedures were done under clinical supervision. After the use of lidocaine-prilocaine cream 5\% (EMLA, AstraZeneca, Södertälje, Sweden) for 2 minutes on dry gum surface, local (for upper molars) or block (for lower molars) anaesthesia was carried out using lidocaine 2\% with adrenaline 1:80000 (Lignospan Special $2 \%$, Septodont, Paris, France). Rubber dam was placed in all patients, throughout the whole procedure. Complete caries removal was carried out using a carbide bur and a sharp spoon excavator removing the peripheral carious dentin first, followed by the part of the dentin that could lead to pulp exposure. If a pulp exposure occurred during complete caries removal, the tooth was eligible for inclusion and was allocated to one of two randomisation groups, independently of the size of the exposed pulp.

In the DPC group, the resulting haemorrhage had to stop with the use of moist with saline cotton pellets in less than two minutes. If needed, the procedure was repeated for additional three minutes to a maximum of five minutes. In the pulpotomy group, similarly, haemostasis should have been achieved at root pulp stumps with the use of moist cotton pellets for two minutes using pressure and repeated for additional three minutes, if needed. In both DPC and pulpotomy groups, after haemostasis was achieved an approximately $1 \mathrm{~mm}$ thick layer of MTA (Medcem $\mathrm{GmbH}$, Weinfelden, Switzerland) was 
applied over and exceeding the pulp exposed areas. The MTA was covered with resin modified glass ionomer cement (RM-GIC; Vitrebond 3M/ESPE, St. Paul, MN, USA) avoiding any pressure. Class I cavities were restored with composite resin (Scotchbond ${ }^{\mathrm{TM}}$ Universal Adhesive and Filtek ${ }^{\mathrm{TM}} \mathrm{Z} 250$ Universal Restorative-both from 3M/ESPE, St. Paul, MN, USA) and class II or multi-surface cavities with a properly fitted stainless steel primary molar crown (3M/ESPE, St. Paul, MN, USA). Post-operative radiographs were taken to determine the proper fitting of the crowns.

\section{Outcome assessment}

All patients enrolled in the trial were reached every six months by phone for their recall appointments and were offered free check-ups and tooth cleaning / fluoridation as rewards for attending these appointments. Each patient was evaluated clinically at every 6-month appointment on the clinical treatment outcome by two calibrated examiners, one of two Clinic supervisors (faculty members) and the first author (DD). Calibration was performed prior to the trial's initiation among outcome assessors until a calculated Cohen's kappa coefficient reached over 0.80 . The radiographic assessment always followed the clinical one. The evaluation of the radiograph could not be performed blindly, due to obvious difference between DPC and pulpotomy. Consensus was reached by the two outcome assessors in all cases before filling the outcome assessment form. The first page of the data form covered the Frankl Scale $(+/++)$, the type of treated tooth (mandibular or maxillary; first or second molar), the cavity type (class I or II), and haemorrhage control (first attempt or second attempt).

At each recall appointment the evaluated clinical parameters included pain (presence / absence), mobility (pathologic / none or appointed to natural exfoliation), restoration condition (presence / absence), periodontal health (healthy / bleeding at probing), contact point (closed / open), occlusal surface (intact / loss of morphology), and secondary caries (presence / absence). In the radiographic evaluation of each tooth, the parameters tested were: disruption of lamina dura (presence / absence), internal root resorption (presence / absence), external root resorption (pathologic / none or appointed to natural exfoliation), pulp canal obliteration (presence / absence), and furcation radiolucency (presence / absence). The primary outcome of this trial was all-cause failure of the restoration for at least one of the abovementioned clinical / radiographic reasons, while the secondary outcomes were each separate clinical / radiographic criterion. If a patient missed one of the scheduled appointments and treatment was successful at the next appointment after 6 months, the previous lost appointment 
was also considered successful (the same if the following appointment was considered a failure). All enrolled patients were re-examined semi-annually to a minimum of 1-year post-treatment. However, this trial was conducted as a Master's thesis and had to be concluded within the framework of the first author's 3-year postgraduate program, which meant that not all patients could be recalled for 2-year and 3-year re-examinations.

\section{Statistical Analysis}

Descriptive statistics were calculated including absolute and relative frequencies for all binary outcomes and means with Standard Deviations (SDs) for continuous patient characteristics. Initial crude differences between groups were assessed with Fisher's exact test. Differences between the randomisation groups in the risk of failure for each criterion were assessed with generalised linear models for the binary family taking into account within-patient clustering of multiple teeth and multiple time-points per patient, with the results being expressed as Relative Risks (RR) and the corresponding 95\% Confidence Intervals (Cl). Additionally, survival analysis was employed to assess all-cause failure, clinical failure, and radiographic failure of the restorations, while accounting for the variable follow-up of each patient. After checking assumptions, Kaplan-Meier survival curves were used to present restorations' survival graphically, while log-rank tests were used to find differences between groups. The failure risk at each time-point was initially assessed with Cox shared frailty regression models. Initially, a univariable model was constructed with experimental group as fixed factor, taking into account within-patient clustering of restorations. Then, the factors patient age, Frankl scale, jaw, molar category, mouth side, cavity category, open cavity presence, haemorrhage control, and the need for repetition of haemorrhage control were regressed as separate factors on restoration failure, and all factors with $\mathrm{P} \leq$ 0.2 were included as covariates in a final multivariable model with the experimental group to adjust for confounding. The results of the survival analyses are presented as Hazard Ratios (HR) and the associated $95 \%$ Cls. Finally, post hoc subgroup analyses were performed to assess the modifying effect of jaw (maxilla or mandible), molar category (first or second molar), and cavity category (occlusal or class II) on restoration failure, including an interaction term for between-subgroup differences. All analyses were run in Stata 14.0 (StataCorp, College Station, TX) with a two-tailed alpha of $5 \%$ and the trial's dataset was made freely available via Zenodo (Dimitraki et al. 2018). 


\section{Results}

\section{Recruitment, participant flow, and numbers analysed}

A total of 74 patients with 97 teeth were enrolled in the trial and treated between September 2013 to September 2015. The patients' mean age was 6.58 years (SD 1.42 years) and 43 of the patients (58\%) were boys. A total of 30 teeth in 24 patients, even though deemed initially eligible, were finally excluded from the trial because of lack of haemorrhage control, absence of pulp involvement during complete caries removal, or due to temporary detachment of the rubber dam during application of the trial's procedures. Eight patients who were randomised and received treatment, dropped out later on--five of them due to relocation to another city / country and three of them due to unwillingness to continue attending the recall appointments. The total number of teeth that were available at each time point for evaluation can be seen in Figure 1 and Table 1.

\section{All-cause, clinical, and radiographic failure}

The overall cumulative all-cause, clinical, and radiographic survival rates for DPC and pulpotomy were calculated for each 6-monthly examination through the 36 months follow up time (Table 2). Survival from all-cause failure was $79.7 \%(95 \% \mathrm{Cl}=69.3 \%-86.9 \%)$ at 12 months and $66.0 \%(95 \% \mathrm{Cl}=53.4 \%$ $76.0 \%)$ at 24 months, which remained stable up to 36 months. All-cause survival was similar for DPC and pulpotomy $(P=1.00)$ and showed a gradual decline from baseline to 24 months of follow up time when they remained steady up to 36 months of follow up time, as shown in Figure 2a. Overall \% survival in the DPC group ranged from $85.0 \%(95 \% \mathrm{Cl}=69.6-99.8 \%)$ in the first 6 post-operative months to $69.7 \%$ $(95 \% \mathrm{Cl}=51.5-82.2 \%)$ at $24-36$ months, while \% survival in the pulpotomy group ranged from $98.3 \%$ in the first 6 post-operative months to $61.5 \%(95 \% \mathrm{Cl}=43.0-75.6 \%)$ at $24-36$ months.

Clinically, both interventions had similar survival rates, with no statistically significant differences between them $(p=0.22)$. The survival rates for both interventions showed gradual declines from the first postoperative period to 24 months when they both stabilised (Figure $2 b$ ). Clinical \% survival in the DPC group ranged from $92.5 \%(95 \% \mathrm{Cl}=78.5-97.5 \%)$ in the first 6 post-operative months to $77.9 \%$ $(95 \% \mathrm{Cl}=58.1-89.2 \%)$ at $24-36$ months, while \% survival in the pulpotomy group ranged from $100.0 \%$ in the first 6 post-operative months to $85.6 \%(95 \% \mathrm{Cl}=64.9-94.6 \%)$ at $24-36$ months.

Radiographically, both interventions showed similar survival when compared with each other or through time, with the differences being not statistically significant $(p=0.84)$. The success rates for 
DPC declined from the first post-operative months up to 18 months follow up time point and remained stable until the end of the study, whereas for the pulpotomy group survival stabilised at the 24 months' time point till the end of the follow up time at 36 months (Figure 2c). Radiographic \% survival in the DPC group ranged from $85.0 \%(95 \% \mathrm{Cl}=69.6-93.0 \%)$ in the first 6 post-operative months to $73.6 \%(95 \%$ $\mathrm{Cl}=56.3-84.9 \%$ ) at 36 months, while $\%$ survival in the pulpotomy group ranged from $98.3 \%$ in the first 6 post-operative months to $68.6 \%(95 \% \mathrm{Cl}=50.7-81.1 \%)$ at the end of the trial period.

\section{Factors associated with restoration failure}

The influence of various potential confounders on restoration survival was assessed through univariable and multivariable regression modelling for all-cause failure, clinical failure, and radiographic failure (Appendix 1). Age did not modify the success rates either clinical $(p=0.57)$, radiographic $(p=0.44)$ or overall $(p=0.24)$ success for both interventions. There was a tendency for open cavity presence to influence negatively all-cause failure in the univariable analysis $(p=0.11)$, which however did not reach the $5 \%$ statistical significance level in the multivariable analysis $(\mathrm{HR}=1.96 ; 95 \% \mathrm{Cl}=0.95-4.05 ; \mathrm{p}=0.07)$.

Regarding clinical failure, univariable analysis indicated that haemostasis control, first and second attempt, were very important factors, as they perfectly predicted clinical failure. Additionally, open cavity presence was significantly associated with failure ( $P$ from univariable analysis $=0.01)$. This was retained as significant factor in the adjusted analysis, where teeth with open cavity were significantly more likely to fail clinically $(\mathrm{HR}=5.80 ; 95 \% \mathrm{Cl}=1.44-23.36 ; \mathrm{P}=0.01)$. Finally, jaw was significantly associated with clinical failure in the univariable analysis $(p=0.04)$, but the multivariable analysis found only a tendency for upper molars to show increased failure $(\mathrm{HR}=3.29 ; 95 \% \mathrm{Cl}=0.84$ 12.99; $p=0.09$ ).

Finally, as far as radiographic failure is concerned, the univariable analysis indicated that tooth type was significantly associated with radiographic failure $(P=0.03)$. This remained however only as a tendency in the adjusted analysis, where the second molars were tendentially less likely to fail than first molars $(\mathrm{HR}=0.47 ; 95 \% \mathrm{Cl}=0.19-1.18 ; \mathrm{P}=0.11)$. Cavity type was tendentially significant predictor of radiographic failure in the univariable analysis $(P=0.15)$, but this tendency faded in the multivariable analysis $(P=0.27)$.

\section{Subgroup analysis}


The effect of jaw, tooth category, and cavity category were also tested as interaction terms together with randomisation group (Appendix 2). Although jaw and tooth category had no significant modifying effect, there were hints that cavity category significantly influenced the effect of treatment $(P<0.001)$. This was further examined by subgroup analysis of all-cause failure by cavity type, which was categorised as class II (mesio-occlusal in second primary molars and disto-occlusal in first primary molars, often extending to lingual/palatal or buccal surface) or occlusal (Appendix 3). For class II cavities the failure risk was similar for DPC and pulpotomy (HR=1.04; $95 \% \mathrm{Cl}=0.45-2.38 ; \mathrm{P}=0.93)$, it was however significantly influenced by the existence of open cavity. For occlusal cavities, failure risk was significantly lower with pulpotomy $(\mathrm{HR}<0.01 ; \mathrm{P}<0.001)$, which was also influenced by the patient's behaviour (assessed with the Frankl Scale). Caution is however warranted in the interpretation of these findings, since only 15 occlusal cavities were included in the present trial.

\section{Separate clinical / radiographic evaluation criteria}

No significant effects were seen regarding the occurrence of tooth mobility, pain, restoration failure, contact points, secondary caries, occlusal surface, loss of lamina dura, and furcation radiolucency (Appendix 4a-4b). There was a small tendency for periodontal health to worsen as observation time passed, but this was not consistent. As far as internal resorption is concerned, less internal resorption cases were seen with post-treatment time $(R R s<1.0 \& P<0.05)$. As far as pathologic external resorption is concerned, a tendency was seen for pulpotomised teeth to show more external resorption than directly capped teeth ( $\mathrm{RR}=3.31 ; 95 \% \mathrm{Cl}=0.93-11.73) ; \mathrm{P}=0.06)$. Physiologic external resorption on the other side increased significantly through the observation period (RRs $>1.0 \& P<0.05)$ and a tendency was seen for lower physiologic external resorption in pulpotomised teeth compared to directly capped teeth $(\mathrm{RR}=0.44 ; 95 \% \mathrm{Cl}=0.16-1.21 ; \mathrm{P}=0.11)$. Finally, for pulp canal obliteration a small transient variation for time was seen ( $P<0.05$ only at 6 months post-treatment), as well as a tendency for higher pulp obliteration in pulpotomised teeth compared to directly capped teeth $(\mathrm{RR}=2.16 ; 95 \% \mathrm{Cl}=0.86-5.43$; $\mathrm{P}=0.10)$.

\section{Discussion}

The results of the present single-centre parallel randomised clinical trial indicated that no significant difference exists in the survival of carious primary molars treated with DPC or pulpotomy. DPC was 
recommended in small traumatic or mechanical pulp exposure, but not in carious pulp exposure of these teeth (AAPD 2014). However, this contraindication has been challenged by some researchers, who suggest that DPC might be a viable alternative for carefully selected cases with minimal to no signs of pulpal inflammation (Sujlana and Pannu 2017). Caicedo et al. (2006) in their short term histological evaluation of a smaller number of teeth which were extracted 6 months after treatment, concluded that favourable histological outcomes were seen with both pulpotomy and DPC with MTA, while the former was tendentially preferable.

Success rates for DPC reported in the literature vary considerably due to differences in the materials, protocols, and follow-up periods. The overall 12-month success rate for DPC using either calcium hydroxide or enamel matrix derivative was reported to be $100 \%$ in the study of Garrocho-Rangel et al (2009). In another study using calcium hydroxide, non-rinse conditioner, total-etch technique, and a self-etch adhesive system (Demir et al. 2007), the overall success rate of DPC was close to $93 \%$. In the study of Fallahinejad Ghajari et al. (2013), after 20 months of follow-up period DPC using CEM and MTA as pulp medicaments, success rates were $89 \%$ and $95 \%$, respectively. In the study of Kotsanos et al. (2014) the cumulative long-term 4-year success rate of DPC in primary molars using a fast setting calcium hydroxide paste was calculated as $80 \%$. Despite insufficient evidence to support the best DPC material, Schwendicke et al. in a recent meta-analysis (2016) suggested MTA as a better choice over calcium hydroxide. However, at the same time no significant difference was found in success rates between MTA, enamel matrix proteins, bonding directly on the exposed pulp without etching, and calcium enriched paste compared to calcium hydroxide (Demir et al. 2007; Tuna and Olmez 2008; Schwendicke et al. 2016).

In the present study, no difference in the survival rates was observed between maxillary and mandibular primary molars in accordance with the study of Tuna and Olmez (2008). However, Subramaniam et al. (2009) assessed pulpotomies done with MTA or formocresol over a 24-month period and reported that all failed cases pertained to first primary molars. Demir and Cehreli (2007) noted that all failures seen with five different DPC protocols were seen in mandibular primary molars (9.5\% in the mandible versus $0 \%$ in the maxilla), while a non-significant tendency was seen for higher failure for the second over the first molars ( $14 \%$ for second versus $4 \%$ for first molars). Lastly, Ulusoy et al. (2014) reported higher failure rate for the mandible over the maxilla (31\% versus $20 \%$, respectively) and inconsistent differences between first and second primary molars. 
On the other side, the type of cavity was significantly associated in the present trial with the outcome of vital pulp therapy, as was shown by a significant interaction term of survival analyses (Appendix 2). This finding is supported by the study of Kassa et al. (2009), who reported that primary teeth with proximal carious lesions extending further than the outer half of the dentine show more extensive inflammatory changes in their pulp compared to occlusal carious lesions of the same depth. Whereas for class II cavities no difference in the survival between DPC and pulpotomy was seen $(P=0.52$; Appendix 3$)$, the outcome of pulpotomy was better than DPC for occlusal cavities $(P<0.001$; Appendix 3). However, as this pertains only to a subgroup of this trial's sample, these results might be underpowered.

A tendency was seen in the present trial for pulpotomised teeth to be associated with higher external resorption than teeth treated with $\mathrm{DPC}(\mathrm{RR}=3.31 ; 95 \% \mathrm{Cl}=0.93-11.73 ; \mathrm{P}=0.06$; Appendix $4 \mathrm{~b})$. Reported rates of external root resorption, internal root resorption, or resorption at the furcation range vary considerably (Cardoso-Silva et al. 2011; Malekafzali et al. 2011). It has been hypothesised that signs of pulp necrosis manifest differently in teeth treated with DPC or those treated with pulpotomy (Caicedo et al. 2006). With DPC, the necrotic tissue may be located in the pulp chamber and furcation radioluscency is more likely to occur, whereas in pulpotomies, the pulp chamber is filled with pulpotomy medicaments and in that case the furcation area is unlikely to be infected and the radicular part of the tooth is expected to fail with periapical pathology more likely to develop (Caicedo et al. 2006). However, it must be noted that not all cases of root resorption are critical for the tooth prognosis. Minimal arrested internal root resorption is compatible with otherwise asymptomatic pulpotomised teeth, which do not necessarily show any signs of clinical failure and can be kept until their physiological exfoliation (Cardoso-Silva et al. 2011).

Finally, a tendency was also seen for pulpotomy to be associated with higher pulp canal obliteration rates compared to $\mathrm{DPC}(\mathrm{RR}=2.16 ; 95 \% \mathrm{Cl}=0.86-5.43 ; \mathrm{P}=0.10 ;$ Appendix $4 \mathrm{~b})$. Generally, pulp canal obliteration is a common radiographic finding after pulpotomy (Agamy et al. 2004; Noorollahian 2008). It is attributed to extensive activity of odontoblast-like cells, demonstrating that the tooth has retained some degree of vitality, and is therefore not regarded as failure (Tziafas et al. 2000). A wide range of pulp canal obliteration has been reported, varying between $25 \%$ and $100 \%$ (Caicedo et al. 2006; Subramaniam et al. 2009; Cardoso-Silva et al. 2011), and has been histologically confirmed (Caicedo et al. 2006). Agamy et al. (2004) reported that both white and grey MTA showed calcifications 
of the residual pulp and increased secondary dentin formation; and concluded that grey MTA shows more favourable results. A meta-analysis comparing pulpotomy with either MTA or formocresol as a dressing (Peng et al. 2006) reported no significant difference in this respect. To the best of our knowledge, there is no report for pulp canal obliteration in DPC of primary molars.

\section{Limitations}

Some potential limitations of the present trial must also be considered. While full blinding was impossible due to radiographic differences in the techniques studied, blinding was always applied during clinical evaluation. Formation of dentinal bridge was not possible to assess due to the overlap of the capping site by the stainless steel crown, which was the chosen restoration in most cases. Despite calibration and supervision of postgraduate students in performing vital pulp treatments, different results may be expected when treatments are done by experienced specialists (Kotsanos et al. 2014). Finally, as only cooperative children were included in the trial, the results of the trial might not be directly extrapolated to non-cooperative children.

\section{Generalisability}

The results of the present trial are applicable to healthy cooperative children of Caucasian descent, aged 3-9 years old.

\section{Conclusions}

The results of the present single-centre parallel randomised trial indicated that both DPC and pulpotomy presented acceptable clinical results, with overall success rate for both materials being $79.7 \%$ at the 1 year follow-up and $66.0 \%$ at the 2- or 3-years follow-up. No significance differences were seen in the 3-year overall failure between the two techniques. 


\section{References}

Agamy HA, Bakry NS, Mounir MMF, Avery DR. Comparison of mineral trioxide aggregate and formocresol as pulp-capping agents in pulpotomized primary teeth. Pediatr Dent. 2004;26:3029.

Agary S, Shirvani A, Fazlyab M. MTA and ferric sulfate in pulpotomy outcomes of primary molars: a systematic review and meta-analysis. J Clin Pediatr Dent. 2014;39:1-8.

American Academy of Pediatric Dentistry. Guideline on pulp therapy for primary and immature permanent teeth, Revised 2014. Pediatric Dentistry. Reference Manual 2014-2015; p. 242-50. www.aapd.org/media/policies guidelines/g pulp.pdf

Asl Aminabadi N, Maljaei E, Erfanparast L, et al. Simvastatin versus calcium hydroxide direct pulp capping of human primary molars: a randomized clinical trial. J Dent Res Dent Clin Dent Prospects 2013;7:8-14.

Bani M, Aktas N, Cinar C, Odabas ME. The clinical and radiographic success of primary molar pulpotomy using biodentine and mineral trioxide aggregate: a 24-month randomized clinical trial. Pediatr Dent. 2017;39:284-8

Caicedo R, Abbott PV, Alongi DJ, Alarcon MY. Clinical, radiographic and histological analysis of the effects of mineral trioxide aggregate used in direct pulp capping and pulpotomies of primary teeth. Aust Dent J. 2006;51:297-305.

Cardoso-Silva C, Barberia E, Maroto M, Garcia-Godoy F. Clinical study of mineral trioxide aggregate in primary molars. Comparison between grey and white MTA - A long term follow-up (84 months). J Dent. 2011;39:187-93.

Coll JA, Seale NS, Vargas K, et al. Primary tooth vital pulp therapy: a systematic review and metaanalysis. Pediatr Dent. 2017;39:16-123.

Dhar V, Marghalani AA, Crystal YO, et al. Use of vital pulp therapies in primary teeth with deep caries lesions. Pediatr Dent. 2017;39:E146-59.

Demir T, Cehreli ZC. Clinical and radiographic evaluation of adhesive pulp capping in primary molars following hemostasis with 1.25\% sodium hypochlorite: 2-year results. Am J Dent. 2007;20:1828. 
Dimitraki D, Papageorgiou SN, Kotsanos N. Direct pulp capping versus pulpotomy with MTA for carious primary molars: a 3-year randomised clinical trial [Data set]. Zenodo. http://doi.org/10.5281/zenodo.1401124.

Duston B, Coll J A. A survey of primary tooth pulp therapy as taught in US dental schools and practiced by diplomats of an American board of pediatric dentistry. Pediatr Dent. 2008;30:42-8.

Dye B, Thornton-Evans G, Li X, lafolla T. Dental caries and sealant prevalence in children and adolescents in the United States, 2011-2012. NCHS Data Brief 2015;191:1-8.

Fallahinejad Ghajari M, Jeddi T A, Iri S, Asgary S. Direct pulp-capping with calcium enriched mixture in primary molar teeth: a randomized clinical trial. Iran Endod J. 2010;5:27-30.

Fallahinejad Ghajari M, Jeddi T A, Iri S, Asgary S. Treatment outcomes of primary molars direct pulp capping after 20 months: a randomized controlled trial. Iran Endod J. 2013;8:149-52.

Farooq NS, Coll JA, Kuwabara A, Shelton P. Success rates of formocresol pulpotomy and indirect pulp therapy in the treatment of deep dentinal caries in primary teeth. Pediatr Dent. 2000;22:278-86.

Fuks AB, Papagiannoulis L. Pulpotomy in primary teeth: Review of the literature according to standardized criteria. Eur Arch Paediatr Dent. 2006;7:64-71.

Fuks AB. Current concepts in vital pulp therapy. Eur J Paediatr Dent. 2002;2:115-20.

Fuks $A B$. Vital pulp therapy with new materials for primary teeth: new directions and treatment perspectives. J Endod. 2008;34:S18-24.

Garrocho-Rangel A, Flores H, Silva-Herzog D, et al. Efficacy of EMD versus calcium hydroxide in direct pulp capping of primary molars: a randomized controlled clinical trial. Oral Surg Oral Med Oral Pathol Oral Radiol Endod. 2009;107:733-8.

Haghgoo R, Asgary S, Abbas FM, Hedeshi RM. Nano-hydroxyapatite and calcium-enriched mixture for pulp capping of sound primary teeth: a randomized clinical trial. Iran Endod J. 2015;10:107-11.

Haghgoo R, Naderi N J. Comparison of calcium hydroxide and bioactive glass after direct pulp capping in primary teeth. J Dent Tehran Tehran Univ. 2007;4:155-9.

Huth KC, Paschos E, Hajek-Al-Khatar N, et al. Effectiveness of 4 pulpotomy techniques - Randomized controlled trial. J Dent Res. 2005;84:1144-8.

Innes N. Better outcomes in pulpotomies on primary molars with MTA. Evid Based Dent. 2007;8:1112. 
Kassa D, Day P, High A, Duggal M. Histological comparison of pulpal inflammation in primary teeth with occlusal or proximal caries. Int J Paediatr Dent. 2009;19:26-33.

Kotsanos N, Arapostathis KN, Arhakis A, Menexes G. Direct pulp capping of carious primary molars. A specialty practice based study. J Clin Pediatr Dent. 2014;38:307-312.

Malekafzali B, Shekarchi F, Asgary S. Treatment outcomes of pulpotomy in primary molars using two endodontic biomaterials. A 2-year randomised clinical trial. Eur J Paediatr Dent. 2011;12:18993.

$\mathrm{Ng}$ FK, Messer LB. Mineral trioxide aggregate as a pulpotomy medicament: A narrative review. Eur Arch Paediatr Dent. 2008;9:4-11.

Noorollahian $\mathrm{H}$. Comparison of mineral trioxide aggregate and formocresol as pulp medicaments for pulpotomieas in primary molars. Br Dent J. 2008;204:E20.

Peng L, Ye L, Tan H, Zhou X. Evaluation of the formocresol versus mineral trioxide aggregate primary molar pulpotomy: a meta-analysis. Oral Surg Oral Med Oral Pathol Oral Radiol Endod. 2006;102:e40- e44.

Rodd HD, Waterhouse PJ, Fuks AB, Fayle SA, Moffat MA. Pulp therapy for primary molars. Int J Paediatr Dent. 2006;16 Suppl 1:15-23.

Rönnerman A. The effect of early loss of primary molars on tooth eruption and space conditions. A longitudinal study. Acta Odontol Scand 1977;35:229-39.

Schwendicke F, Brouwer F, Schwendicke A, Paris S. Different materials for direct pulp capping: systematic review and meta-analysis and trial sequencial analysis. Clin Oral Investig. 2016;20:1121-32.

Shayegan A, Atash R, Petein M, Abbeele AV. Nanohydroxyapatite used as a pulpotomy and direct pulp capping agent in primary pig teeth. J Dent Child (Chic). 2010;77:77-83.

Smaïl-Faugeron V, Glenny AM, Courson F, Durieux P, Muller-Bolla M, Fron Chabouis H. Pulp treatment for extensive decay in primary teeth. Cochrane Database Syst Rev. 2018;5:CD003220.

Sonmez D, Sari S, Cetinbas T. A comparison of four pulpotomy techniques in primary molars: a longterm follow-up. J Endod. 2008;34:950-5.

Subramaniam P, Konde S, Mathew S, Sugnami S. Mineral trioxide aggregate as pulp capping agent for primary teeth pulpotomy: 2 year follow up study. J Clin Pediatr Dent. 2009;33:311-4. 
Sujlana A, Pannu PK. Direct pulp capping: A treatment option in primary teeth? Pediatr Dent J. $2017 ; 27: 1-7$.

Tuna D, Olmez A. Clinical long-term evaluation of MTA as a direct pulp capping material in primary teeth. Int Endod J. 2008;41:273-278.

Tziafas $\mathrm{D}$, Smith AJ, Lesot $\mathrm{H}$. Designing new treatment strategies in vital pulp therapy. J Dent. 2000;28:77-92.

Ulusoy AT, Bayrak S, Bodrumlu EH. Clinical and radiological evaluation of calcium sulfate as direct pulp capping material in primary teeth. Eur J Paediatr Dent. 2014;15:127-31.

Vostatek S, Kanellis M, Weber-Gasparoni K, Gregorsok RL. Sodium hypochlorite pulpotomies in primary teeth: A retrospective assessment. Pediatr Dent. 2011;33:329-32. 


\section{Figure legends}

Fig. 1 CONSORT flow diagram.

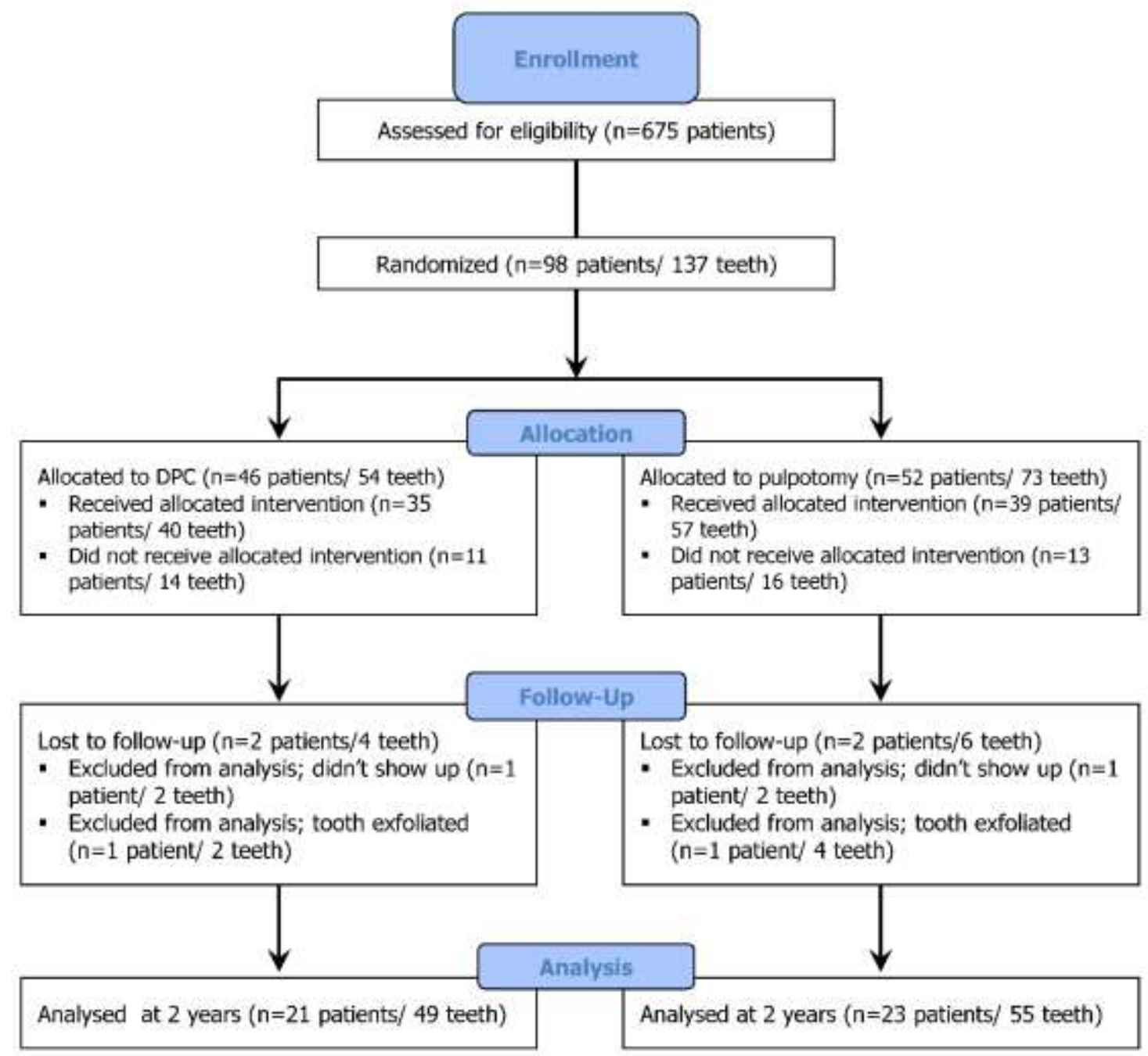


Fig. 2a Cumulative all-cause survival (blue line: direct pulp capping, red line: pulpotomy). Coloured numbers within the figure indicate net loss (failurures and drop-outs) at each time-point.
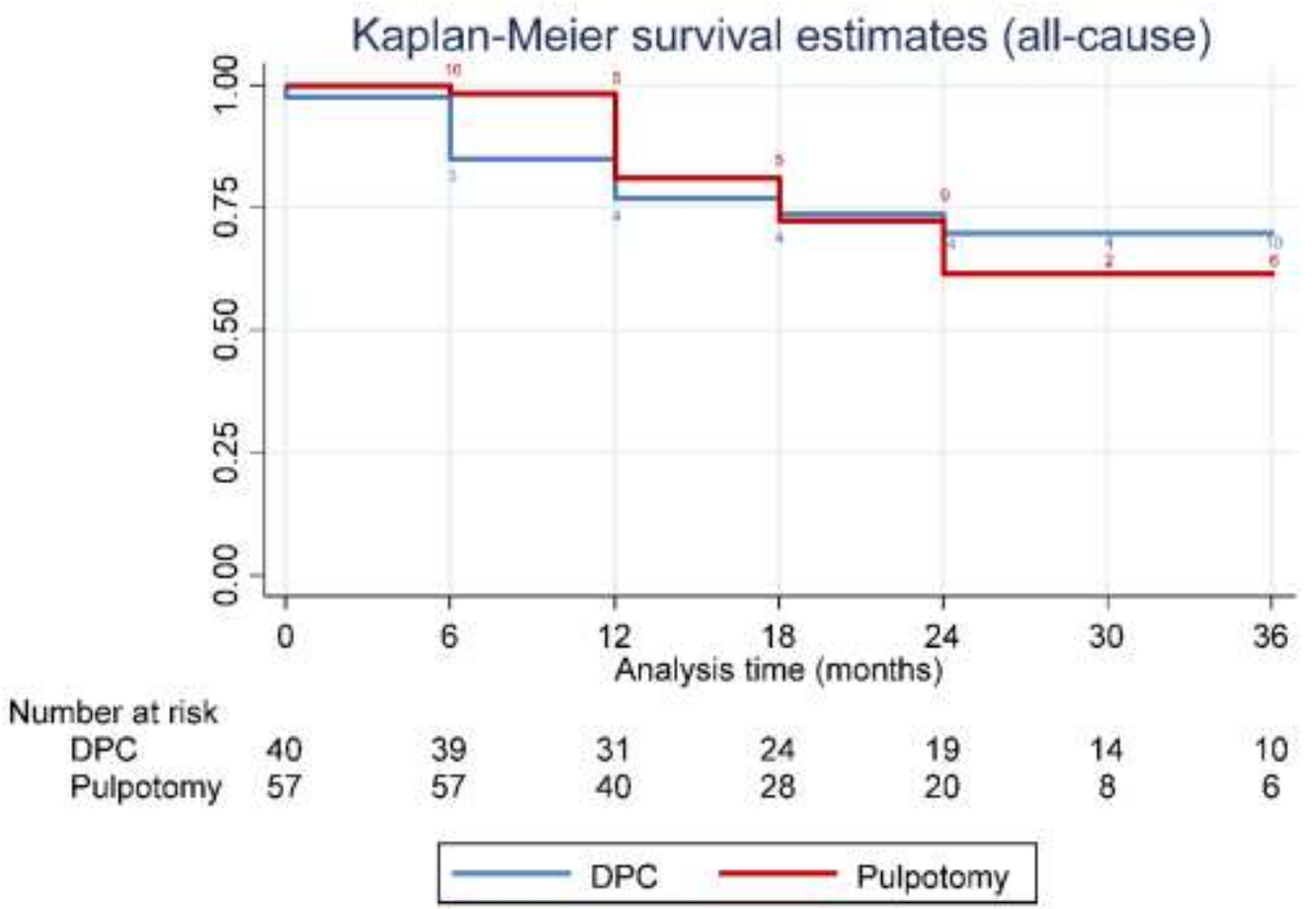

Fig. 2b Cumulative clinical survival (blue line: direct pulp capping, red line: pulpotomy). Coloured numbers within the figure indicate net loss (failurures and drop-outs) at each time-point.

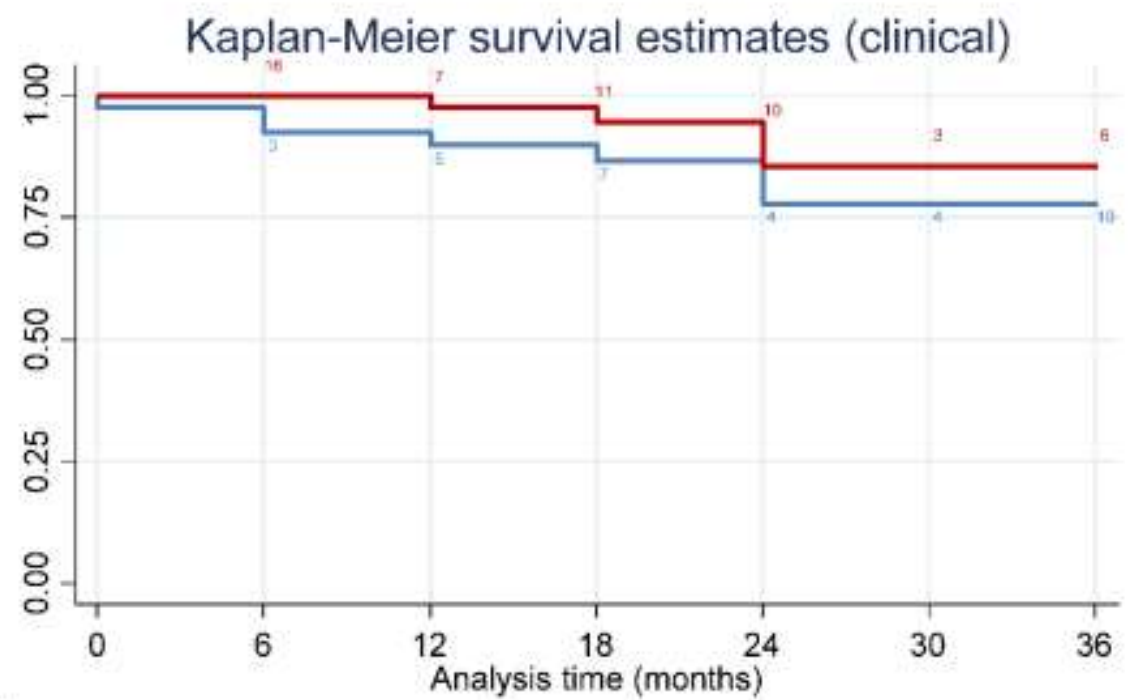

Number at risk

\begin{tabular}{lccccccc} 
DPC & 40 & 39 & 34 & 28 & 20 & 14 & 10 \\
Pulpotomy & 57 & 57 & 41 & 33 & 21 & 9 & 6 \\
& & & & & \\
\cline { 4 - 6 } & & DPC & Pulpotomy &
\end{tabular}


Fig. 2c Cumulative radiographical survival (blue line: direct pulp capping, red line: pulpotomy). Coloured numbers within the figure indicate net loss (failurures and drop-outs) at each time-point.

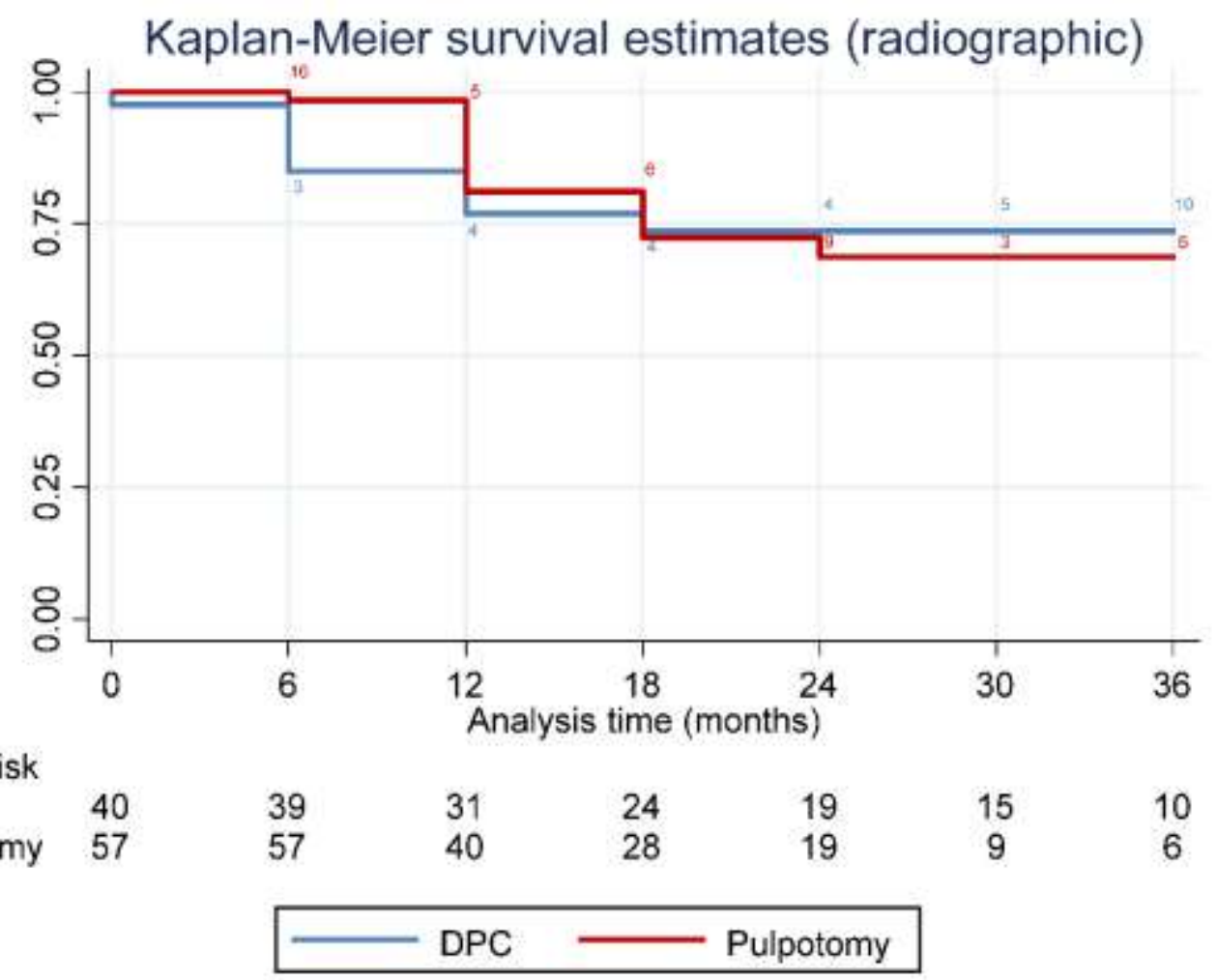


TABLES

Table 1 Number of teeth available for examination at each time

\begin{tabular}{|l|l|l|l|l|l|l|l|}
\hline Group & Baseline & $\mathbf{6}$ months & $\mathbf{1 2}$ months & $\mathbf{1 8}$ months & $\mathbf{2 4}$ months & $\mathbf{3 0}$ months & $\mathbf{3 6}$ months \\
\hline DPC & 40 & 36 & 27 & 22 & 16 & 10 & 6 \\
\hline Pulpotomy & 57 & 41 & 33 & 28 & 16 & 13 & 9 \\
\hline Total & 97 & 77 & 60 & 50 & 32 & 23 & 15 \\
\hline
\end{tabular}

DPC direct pulp capping 
Table 2. All-cause, clinical, and radiographic \% survival rates in the two groups at each timepoint.

\begin{tabular}{|l|l|l|l|l|l|l|l|}
\hline & \multicolumn{2}{|c|}{ All-cause } & \multicolumn{2}{c|}{ Clinical } & \multicolumn{2}{c|}{ Radographic } \\
\hline & \multicolumn{1}{|c|}{ DPC } & \multicolumn{1}{|c|}{ Pulpotomy } & \multicolumn{1}{c|}{ DPC } & \multicolumn{1}{c|}{ Pulpotomy } & \multicolumn{2}{|c|}{ DPC } & \multicolumn{1}{c|}{ Pulpotomy } \\
\hline & Survival (95\% Cl) & Survival (95\% Cl) & Survival (95\% Cl) & Survival (95\% Cl) & Survival (95\% Cl) & Survival (95\% Cl) \\
\hline 6 months & $85.0(69.6-93.0)$ & $98.3(88.2-99.8)$ & $92.5(78.5-97.5)$ & $100.0(-)$ & $85.0(69.6-93.0)$ & $98.3(88.2-100.0)$ \\
\hline 12 months & $76.8(60.0-87.2)$ & $81.1(65.5-90.1)$ & $89.8(75.0-96.0)$ & $97.6(83.9-100.0)$ & $76.8(60.0-87.2)$ & $81.1(65.5-90.1)$ \\
\hline 24 months & $69.7(51.5-82.2)$ & $61.5(43.0-75.6)$ & $77.9(58.1-89.2)$ & $85.6(64.9-94.6)$ & $73.6(56.3-84.9)$ & $68.6(50.7-81.1)$ \\
\hline 30 months & $69.7(51.5-82.2)$ & $61.5(43.0-75.6)$ & $77.9(58.1-89.2)$ & $85.6(64.9-94.6)$ & $73.6(56.3-84.9)$ & $68.6(50.7-81.1)$ \\
\hline 36 months & $69.7(51.5-82.2)$ & $61.5(43.0-75.6)$ & $77.9(58.1-89.2)$ & $85.6(64.9-94.6)$ & $73.6(56.3-84.9)$ & $68.6(50.7-81.1)$ \\
\hline P value & $73.6(56.3-84.9)$ & $72.4(55.4-83.8)$ & $86.6(70.5-94.2)$ & $94.6(80.0-98.6)$ & $73.6(56.3-84.9)$ & $72.4(55.4-83.8)$ \\
\hline
\end{tabular}

Cl confidence interval, DPC direct pulp capping 


\section{Direct pulp capping versus pulpotomy with MTA for carious primary molars: a randomized clinical trial}

Appendix 1 Univariable and multivariable regression analyses on the effect of treatment and various confounders

\begin{tabular}{|c|c|c|c|c|c|c|c|c|c|c|c|c|c|c|c|c|c|c|c|}
\hline & & \multicolumn{6}{|c|}{ All-cause failure } & \multicolumn{6}{|c|}{ Clinical failure } & \multicolumn{6}{|c|}{ Radiographic failure } \\
\hline & & \multicolumn{3}{|c|}{ Univariable } & \multicolumn{3}{|c|}{ Multivariable } & \multicolumn{3}{|c|}{ Univariable } & \multicolumn{3}{|c|}{ Multivariable } & \multicolumn{3}{|c|}{ Univariable } & \multicolumn{3}{|c|}{ Multivariable } \\
\hline & & HR & $95 \% \mathrm{Cl}$ & $\mathbf{P}$ & HR & $95 \% \mathrm{Cl}$ & $\mathbf{P}$ & HR & $95 \% \mathrm{Cl}$ & $\mathbf{P}$ & HR & $95 \% \mathrm{Cl}$ & $\mathbf{P}$ & HR & $95 \% \mathrm{Cl}$ & $\mathbf{P}$ & HR & $95 \% \mathrm{Cl}$ & $\mathbf{P}$ \\
\hline \multirow[t]{2}{*}{ Intervention } & DPC & Ref & - & - & Ref & - & - & Ref & - & - & Ref & - & - & Ref & - & - & Ref & & - \\
\hline & Pulpotomy & 1.00 & $0.46-2.20$ & 1.00 & 0.95 & $0.45-2.01$ & 0.88 & 0.47 & $0.14-1.59$ & 0.23 & 0.74 & $0.19-2.92$ & 0.66 & 0.92 & $0.39-2.20$ & 0.86 & 0.80 & $0.36-1.82$ & 0.60 \\
\hline \multirow{3}{*}{ Age } & & & & & & & & & & & & & & & & & & & \\
\hline & & & & 0.24 & $\mathrm{nt}$ & & & & & 0.57 & $\mathrm{nt}$ & & & & & 0.44 & nt & & \\
\hline & & & & & & & & & & & & & & & & & & & \\
\hline \multirow[t]{3}{*}{ Frankl } & ++ & Ref & - & - & Ref & - & - & Ref & - & - & Ref & - & - & Ref & - & - & Ref & - & - \\
\hline & + & & & 0.27 & $\mathrm{nt}$ & & & & & 0.27 & $\mathrm{nt}$ & & & & & 0.48 & nt & & \\
\hline & & & & & & & & & & & & & & & & & & & \\
\hline \multirow[t]{3}{*}{ Jaw } & Mandible & Ref & - & - & Ref & - & - & Ref & - & - & Ref & - & - & Ref & - & - & Ref & - & - \\
\hline & Maxilla & & & 0.42 & $\mathrm{nt}$ & & & & & 0.04 & 3.29 & $0.84-12.99$ & 0.09 & & & 0.38 & $\mathrm{nt}$ & & \\
\hline & & & & & & & & & & & & & & & & & & & \\
\hline \multirow[t]{2}{*}{ Molar } & $1^{\text {st }}$ & Ref & - & - & Ref & - & - & Ref & - & - & Ref & - & - & Ref & - & - & Ref & - & - \\
\hline & $2^{\text {nd }}$ & & & 0.14 & 0.70 & \begin{tabular}{|l|}
$0.32-1.54$ \\
\end{tabular} & 0.38 & & & 0.76 & $\mathrm{nt}$ & & & & & 0.03 & 0.47 & $0.19-1.18$ & 0.11 \\
\hline \multirow{4}{*}{ Side } & & & & & & & & & & & & & & & & & & & \\
\hline & Left & Ref & - & - & Ref & - & - & Ref & - & - & Ref & - & - & Ref & - & - & Ref & - & - \\
\hline & Right & & & 0.65 & $\mathrm{nt}$ & & & & & 0.15 & 0.58 & $0.16-2.15$ & 0.41 & & & 0.87 & $\mathrm{nt}$ & & \\
\hline & & & & & & & & & & & & & & & & & & & \\
\hline \multirow[t]{3}{*}{ Cavity } & $1-2$ & Ref & - & - & Ref & - & - & Ref & - & - & Ref & - & - & Ref & - & - & Ref & - & - \\
\hline & 3 & & & 0.20 & 0.39 & \begin{tabular}{|l|}
$0.08-1.81$ \\
\end{tabular} & 0.23 & & & 0.41 & $\mathrm{nt}$ & & & & & 0.15 & 0.29 & $0.03-2.63$ & 0.27 \\
\hline & & & & & & & & & & & & & & & & & & & \\
\hline \multirow[t]{2}{*}{ Open pulp } & No & Ref & - & - & Ref & - & - & Ref & - & - & Ref & - & - & Ref & - & - & Ref & - & - \\
\hline & Yes & & & 0.11 & 1.96 & \begin{tabular}{|c|}
$0.95-4.05$ \\
\end{tabular} & 0.07 & & & 0.01 & 5.80 & $1.44-23.36$ & 0.01 & & & 0.26 & $\mathrm{nt}$ & & \\
\hline & & & & & & & & & & & & & & & & & & & \\
\hline \multirow[t]{3}{*}{ Hemostasis } & Yes & Ref & - & - & Ref & - & - & Ref & - & - & Ref & - & - & Ref & - & - & Ref & - & - \\
\hline & No & & & 0.40 & $\mathrm{nt}$ & & & & & $<0.001$ & $>100$ & - & $<0.001$ & & & 0.40 & $\mathrm{nt}$ & & \\
\hline & & & & & & & & & & & & & & & & & & & \\
\hline \multirow[t]{2}{*}{ Rep. control } & No & Ref & - & - & Ref & - & - & Ref & - & - & Ref & - & - & Ref & - & - & Ref & - & - \\
\hline & Yes & & & 0.40 & $\mathrm{nt}$ & & & & & $<0.001$ & 1 & - & - & & & 0.40 & $\mathrm{nt}$ & & \\
\hline
\end{tabular}

$\mathrm{Cl}$ confidence interval, $D P C$ direct pulp capping, $H R$ hazard ratio, $n t$ not tested, Ref reference category 
Appendix 2 Interaction terms tested for restoration survival function with randomization group

\begin{tabular}{|l|l|l|l|}
\hline Interaction factor & $\begin{array}{l}\text { All-cause } \\
\text { failure }\end{array}$ & $\begin{array}{l}\text { Clinical } \\
\text { failure }\end{array}$ & $\begin{array}{l}\text { Radiographic } \\
\text { failure }\end{array}$ \\
\hline Jaw (mandible vs maxilla) & 0.49 & 0.20 & 0.75 \\
\hline Molar $\left(1^{\text {st }}\right.$ vs $\left.2^{\text {nd }}\right)$ & 0.31 & 0.29 & 0.38 \\
\hline Cavity (mesial/distal vs occlusal) & $<0.001$ & $<0.001$ & $<0.001$ \\
\hline
\end{tabular}


Appendix 3 Univariable and multivariable regression analyses on the effect of treatment and various confounders stratified for mesio-distal cavities

\begin{tabular}{|c|c|c|c|c|c|c|c|c|c|c|c|c|c|}
\hline & & \multicolumn{6}{|c|}{ All-cause failure; mesiodistal cavities } & \multicolumn{6}{|c|}{ All-cause failure; occlusal cavities } \\
\hline & & \multicolumn{3}{|c|}{ Univariable } & \multicolumn{3}{|c|}{ Multivariable } & & & & & & \\
\hline & & HR & $95 \% \mathrm{Cl}$ & $\mathbf{P}$ & HR & $95 \% \mathrm{Cl}$ & $\mathbf{P}$ & HR & $95 \% \mathrm{Cl}$ & $\mathbf{P}$ & HR & $95 \% \mathrm{Cl}$ & $\mathbf{P}$ \\
\hline Intervention & DPC & Ref & - & - & Ref & - & - & Ref & - & - & Ref & - & - \\
\hline & Pulpotomy & 1.00 & $0.43-2.32$ & 1.00 & 1.04 & $0.45-2.38$ & 0.93 & $<0.01$ & $<0.01$ & $<0.001$ & $<0.01$ & $<0.01$ & $<0.001$ \\
\hline & & & & & & & & & & & & & \\
\hline Age & & & & 0.37 & & & & & & 0.32 & $\mathrm{nt}$ & & \\
\hline & & & & & & & & & & & & & \\
\hline Frankl & ++ & Ref & - & - & Ref & - & - & Ref & - & - & Ref & - & - \\
\hline & + & & & 0.61 & & & & & & $<0.001$ & $>100$ & $>100$ & $<0.001$ \\
\hline & & & & & & & & & & & & & \\
\hline Jaw & Mandible & Ref & - & - & Ref & - & - & Ref & - & - & Ref & - & - \\
\hline & Maxilla & & & 0.30 & & & & & & $<0.001$ & 2.87 & $0.38-21.92$ & 0.31 \\
\hline & & & & & & & & & & & & & \\
\hline Molar & $1^{\text {st }}$ & Ref & - & - & Ref & - & - & Ref & - & - & Ref & - & - \\
\hline & $2^{\text {nd }}$ & & & 0.44 & & & & & & 0.19 & 0.71 & $0.07-7.20$ & 0.77 \\
\hline & & & & & & & & & & & & & \\
\hline Side & Left & Ref & - & - & Ref & - & - & Ref & - & - & Ref & - & - \\
\hline & Right & & & 0.63 & & & & & & 0.98 & nt & & \\
\hline & & & & & & & & & & & & & \\
\hline Open pulp & No & Ref & - & - & Ref & - & - & Ref & - & - & Ref & - & - \\
\hline & Yes & & & 0.16 & 1.78 & $0.81-3.92$ & 0.15 & & & $<0.001$ & & & \\
\hline Hemostasis & Yes & Ref & - & - & Ref & - & - & Ref & - & - & Ref & - & - \\
\hline & No & & & 0.51 & & & & & & 1.00 & nt & & \\
\hline & & & & & & & & & & & & & \\
\hline Rep. control & No & Ref & - & - & Ref & - & - & Ref & - & - & Ref & - & - \\
\hline & Yes & & & 0.51 & & & & & & 1.00 & nt & & \\
\hline
\end{tabular}

$\mathrm{Cl}$ confidence interval, $D P C$ direct pulp capping, $H R$ hazard ratio, $n t$ not tested, Ref reference category 
Appendix 4a. Binary regression analysis on each separate clinical / radiographic criterion used for the evaluation of the restorations.

\begin{tabular}{|c|c|c|c|c|c|c|c|c|c|c|c|c|c|c|}
\hline & \multicolumn{2}{|c|}{ Mobility } & \multicolumn{2}{|c|}{ Pain } & \multicolumn{2}{|c|}{ Represent. } & \multicolumn{2}{|c|}{ Contact point } & \multicolumn{2}{|c|}{ Secondary caries } & \multicolumn{2}{|c|}{$\begin{array}{l}\text { Occlusal } \\
\text { surface }\end{array}$} & \multicolumn{2}{|c|}{ Periodontal health } \\
\hline & $\begin{array}{l}\text { RR } \\
(95 \% \mathrm{Cl})\end{array}$ & $\mathbf{P}$ & $\begin{array}{l}\text { RR } \\
(95 \% \mathrm{Cl})\end{array}$ & $\mathbf{P}$ & $\begin{array}{l}\text { RR } \\
(95 \% \mathrm{Cl})\end{array}$ & $\mathbf{P}$ & $\begin{array}{l}\text { RR } \\
(95 \% \mathrm{Cl})\end{array}$ & $\mathbf{P}$ & $\begin{array}{l}\text { RR } \\
(95 \% \mathrm{Cl})\end{array}$ & $\mathbf{P}$ & $\begin{array}{l}\text { RR } \\
(95 \% \text { Cl) }\end{array}$ & $\mathbf{P}$ & $\begin{array}{l}\text { RR } \\
(95 \% \mathrm{Cl})\end{array}$ & $\mathbf{P}$ \\
\hline DPC & Ref & & Ref & & Ref & & Ref & & Ref & & Ref & & Ref & \\
\hline Pulpotomy & $\begin{array}{l}0.65 \\
(0.15-2.81)\end{array}$ & 0.56 & $\begin{array}{l}1.00 \\
(-)\end{array}$ & - & $\begin{array}{l}1.04 \\
(0.98-1.11)\end{array}$ & 0.20 & $\begin{array}{l}0.41 \\
(0.07-2.27)\end{array}$ & 0.31 & $\begin{array}{l}0.66 \\
(0.08-5.49)\end{array}$ & 0.70 & NA & - & $\begin{array}{l}1.09 \\
(0.66-1.78)\end{array}$ & 0.74 \\
\hline Rocolinn & Rof & & Rof & & Rof & & Rf & & Rof & & Rof & & Rof & \\
\hline 6 months & 0.56 & 0.61 & 0.61 & 0.73 & $\begin{array}{l}\text { Ret } \\
1.03 \\
097-1099\end{array}$ & 0.37 & Ret & 0.32 & $\begin{array}{l}\text { ReI } \\
1.00\end{array}$ & - & Ref & - & $\begin{array}{l}\text { Ret } \\
0.67\end{array}$ & 0.05 \\
\hline 12 months & $\begin{array}{l}(0.06-5.13) \\
0.48 \\
(0.04-5.14)\end{array}$ & 0.55 & $\begin{array}{l}(0.04-10.35) \\
1.00 \\
(-)\end{array}$ & - & $\begin{array}{l}(0.9 /-1.09) \\
1.00 \\
(-)\end{array}$ & - & $\begin{array}{l}(0.03-3.04) \\
0.84 \\
(0.14-5.06)\end{array}$ & 0.85 & $\begin{array}{l}(-) \\
0.24 \\
(0.02-3.80)\end{array}$ & 0.31 & - & - & $\begin{array}{l}(0.45-1.00) \\
0.76 \\
(0.50-1.15)\end{array}$ & 0.20 \\
\hline 18 months & $\begin{array}{l}1.15 \\
(0.12-11.01)\end{array}$ & 0.91 & $\begin{array}{l}1.00 \\
(-)\end{array}$ & - & $\begin{array}{l}1.00 \\
(-)\end{array}$ & - & $\begin{array}{l}0.98 \\
(0.16-6.02)\end{array}$ & 0.99 & $\begin{array}{l}0.87 \\
(0.09-8.32)\end{array}$ & 0.90 & - & - & $\begin{array}{l}0.79 \\
(0.48-1.29)\end{array}$ & 0.34 \\
\hline 24 months & $\begin{array}{l}0.88 \\
(0.08-9.57)\end{array}$ & 0.92 & $\begin{array}{l}1.00 \\
(-)\end{array}$ & - & $\begin{array}{l}1.00 \\
(-)\end{array}$ & - & $\begin{array}{l}1.00 \\
(-)\end{array}$ & - & $\begin{array}{l}0.88 \\
(0.19-4.06)\end{array}$ & 0.87 & - & - & $\begin{array}{l}0.72 \\
(0.39-1.31)\end{array}$ & 0.28 \\
\hline 30 months & $\begin{array}{l}2.52 \\
(0.28-22.82)\end{array}$ & 0.41 & $\begin{array}{l}1.00 \\
(-)\end{array}$ & - & $\begin{array}{l}1.00 \\
(-)\end{array}$ & - & $\begin{array}{l}1.00 \\
(-)\end{array}$ & - & $\begin{array}{l}1.26 \\
(0.33-4.84)\end{array}$ & 0.73 & - & - & $\begin{array}{l}0.63 \\
(0.27-1.49)\end{array}$ & 0.29 \\
\hline 36 months & $\begin{array}{l}1.00 \\
(-)\end{array}$ & - & $\begin{array}{l}1.00 \\
(-)\end{array}$ & - & $\begin{array}{l}1.00 \\
(-)\end{array}$ & - & $\begin{array}{l}1.00 \\
(-)\end{array}$ & - & $\begin{array}{l}1.00 \\
(-)\end{array}$ & - & - & - & $\begin{array}{l}0.41 \\
(0.10-1.66)\end{array}$ & 0.21 \\
\hline
\end{tabular}

$\mathrm{Cl}$, confidence interval; DPC, direct pulp capping; NA, not applicable; Ref, reference; RR, relative risk. 
Appendix 4b. Binary regression analysis on each separate clinical / radiographic criterion used for the evaluation of the restorations.

\begin{tabular}{|c|c|c|c|c|c|c|c|c|c|c|c|c|}
\hline & \multicolumn{2}{|c|}{ Lamina dura loss } & \multicolumn{2}{|c|}{ Internal resorption } & \multicolumn{2}{|c|}{ External resorption } & \multicolumn{2}{|c|}{$\begin{array}{c}\text { External resorption } \\
\text { (normal) }\end{array}$} & \multicolumn{2}{|c|}{ Pulp obliteration } & \multicolumn{2}{|c|}{$\begin{array}{c}\text { Furcation } \\
\text { radiolucency }\end{array}$} \\
\hline & $\begin{array}{l}\text { RR } \\
(95 \% \mathrm{Cl})\end{array}$ & $\mathbf{P}$ & \begin{tabular}{|l} 
RR \\
(95\% Cl)
\end{tabular} & $\mathbf{P}$ & $\begin{array}{l}\text { RR } \\
(95 \% \mathrm{Cl})\end{array}$ & $\mathbf{P}$ & $\begin{array}{l}\text { RR } \\
(95 \% \mathrm{Cl})\end{array}$ & $P$ & $\begin{array}{l}\text { RR } \\
(95 \% \mathrm{Cl})\end{array}$ & $\mathbf{P}$ & $\begin{array}{l}\text { RR } \\
(95 \% \mathrm{Cl}) \\
\end{array}$ & $\mathbf{P}$ \\
\hline DPC & Ref & & Ref & & Ref & & Ref & & Ref & & Ref & \\
\hline Pulpotomy & $\begin{array}{l}1.37 \\
(0.36-5.23)\end{array}$ & 0.65 & $\begin{array}{l}0.70 \\
(0.11-4.48) \\
\end{array}$ & 0.70 & $\begin{array}{l}3.31 \\
(0.93-11.73) \\
\end{array}$ & 0.06 & $\begin{array}{l}0.44 \\
(0.16-1.21)\end{array}$ & 0.11 & $\begin{array}{l}2.16 \\
(0.86-5.43)\end{array}$ & 0.10 & $\begin{array}{l}0.70 \\
(0.17-2.80) \\
\end{array}$ & 0.61 \\
\hline Ropoling & Bef & & Ref & & Rof & & 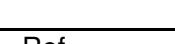 & & Raf & & Rof & \\
\hline 6 monthe & 0.20 & 010 & 0.26 & 001 & $\begin{array}{r}\text { Rer } \\
0.41\end{array}$ & 018 & $\begin{array}{r}\mathrm{nel} \\
3.04\end{array}$ & 012 & $\begin{aligned} \text { Rer } \\
0.41\end{aligned}$ & (2008 & $\begin{aligned} \text { Ret } \\
0.59\end{aligned}$ & 065 \\
\hline 6 months & $(0.03-1.35)$ & 0.10 & $(0.09-0.74)$ & 0.01 & $(0.11-1.52)$ & 0.18 & $(0.76-12.13)$ & 0.12 & $(0.21-0.79)$ & 0.008 & $(0.06-5.45)$ & 0.65 \\
\hline 12 months & $\begin{array}{l}0.50 \\
(0.10-2.57)\end{array}$ & 0.41 & $\begin{array}{l}0.33 \\
(0.12-0.91)\end{array}$ & 0.03 & $\begin{array}{l}0.89 \\
(0.28-2.83) \\
\end{array}$ & 0.84 & $\begin{array}{l}6.17 \\
(1.34-28.35) \\
\end{array}$ & 0.02 & $\begin{array}{l}0.81 \\
(0.45-1.45)\end{array}$ & 0.47 & $\begin{array}{l}0.75 \\
(0.08-7.04) \\
\end{array}$ & 0.80 \\
\hline 18 months & $\begin{array}{l}0.45 \\
(0.10-2.01)\end{array}$ & 0.30 & $\begin{array}{l}0.30 \\
(0.11-0.79)\end{array}$ & 0.02 & $\begin{array}{l}1.07 \\
(0.34-3.36)\end{array}$ & 0.90 & $\begin{array}{l}8.30 \\
(1.83-37.68)\end{array}$ & 0.006 & $\begin{array}{l}0.74 \\
(0.42-1.32)\end{array}$ & 0.31 & $\begin{array}{l}0.60 \\
(0.06-6.43)\end{array}$ & 0.67 \\
\hline 24 months & $\begin{array}{l}0.24 \\
(0.04-1.50)\end{array}$ & 0.13 & $\begin{array}{l}0.45 \\
(0.27-0.75)\end{array}$ & 0.002 & $\begin{array}{l}1.05 \\
(0.30-3.66)\end{array}$ & 0.94 & $\begin{array}{l}11.31 \\
(2.49-51.41)\end{array}$ & 0.002 & $\begin{array}{l}1.24 \\
(0.79-1.94)\end{array}$ & 0.35 & $\begin{array}{l}1.00 \\
(-)\end{array}$ & - \\
\hline 30 months & $\begin{array}{l}1.00 \\
(-)\end{array}$ & - & $\begin{array}{l}0.65 \\
(0.44-0.95)\end{array}$ & 0.03 & $\begin{array}{l}1.73 \\
(0.72-4.15)\end{array}$ & 0.22 & $\begin{array}{l}10.61 \\
(2.18-51.72)\end{array}$ & 0.003 & $\begin{array}{l}1.01 \\
(0.69-1.49)\end{array}$ & 0.95 & $\begin{array}{l}1.28 \\
(0.09-19.06)\end{array}$ & 0.86 \\
\hline 36 months & $\begin{array}{l}1.00 \\
(-)\end{array}$ & - & $\begin{array}{l}1.00 \\
(-)\end{array}$ & - & $\begin{array}{l}1.00 \\
(-)\end{array}$ & - & $3.82-88.03$ & $<0.001$ & $\begin{array}{l}1.00 \\
(-)\end{array}$ & - & $\begin{array}{l}1.00 \\
(-)\end{array}$ & - \\
\hline
\end{tabular}

$\mathrm{Cl}$, confidence interval; DPC, direct pulp capping; NA, not applicable; Ref, reference; RR, relative risk. 